\title{
The Hyperthermophilic Euryarchaeota Pyrococcus abyssi Likely Requires the Two DNA Polymerases D and B for DNA Replication
}

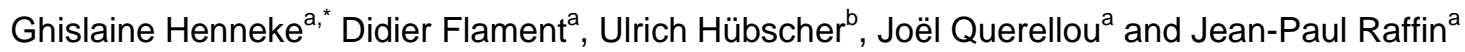

a : IFREMER, UMR 6197, Laboratoire de Microbiologie et Environnements Extrêmes, DRV/VP/LM2E, BP 70, F29280 Plouzané, France

b : Institute of Veterinary Biochemistry, Universität of Zürich, Winterthurerstrasse 190, CH-8057 Zürich,

Switzerland

*: Corresponding author : Ghislaine HENNEKE, Ifremer, DRV/VP/LM2E, B.P. 70, 29280 Plouzané, France;

Tel.: +332 282246 09; Fax: +33 2982247 57; E-mail: ghenneke@ifremer.fr

\begin{abstract}
:
DNA polymerases carry out DNA synthesis during DNA replication, DNA recombination and DNA repair. During the past five years, the number of DNA polymerases in both eukarya and bacteria has increased to at least 19 and multiple biological roles have been assigned to many DNA polymerases. Archaea, the third domain of life, on the other hand, have only a subset of the eukaryotic-like DNA polymerases. The diversity among the archaeal DNA polymerases poses the intriguing question of their functional tasks. Here, we focus on the two identified DNA polymerases, the family B DNA polymerase $\mathrm{B}($ PabpolB) and the family D DNA polymerase D (PabpolD) from the hyperthermophilic euryarchaeota Pyrococcus abyssi. Our data can be summarized as follows: (i) both Pabpols are DNA polymerizing enzymes exclusively; (ii) their DNA binding properties as tested in gel shift competition assays indicated that PabpolD has a preference for a primed template; (iii) PabPolD is a primerdirected DNA polymerase independently of the primer composition whereas PabpolB behaves as an exclusively DNA primer-directed DNA polymerase; (iv) PabPCNA is required for PabpolD to perform efficient DNA synthesis but not PabpolB; (v) PabpolD, but not PabpolB, contains strand displacement activity; (vii) in the presence of PabPCNA, however, both Pabpols D and B show strand displacement activity; and (viii) we show that the direct interaction between PabpolD and PabPCNA is DNAdependent. Our data imply that PabPolD might play an important role in DNA replication likely together with PabpolB, suggesting that archaea require two DNA polymerases at the replication fork.
\end{abstract}

Keywords: DNA replication; euryarchaea; gap filling; strand displacement; DNA polymerase 


\section{Summary}

DNA polymerases carry out DNA synthesis during DNA replication, DNA recombination and DNA repair. During the past five years, the number of DNA polymerases in both eukarya and bacteria has increased to at least 19 and multiple biological roles have been assigned to many DNA polymerases. Archaea, the third domain of life, on the other hand, have only a subset of the eukaryotic-like DNA polymerases. The diversity among the archaeal DNA polymerases poses the intriguing question of their functional tasks. Here we focus on the two identified DNA polymerases, the family B DNA polymerase B (PabpolB) and the family D DNA polymerase D (PabpolD) from the hyperthermophilic euryarchaeota Pyrococcus abyssi. Our data can be summarised as follows: (i) both Pabpols are DNA polymerizing enzymes exclusively; (ii) their DNA binding properties as tested in gel shift competition assays indicated that PabpolD has a preference for a primed-template; (iii) PabPolD is a primer-directed DNA polymerase independently of the primer composition whereas PabpolB behaves as an exclusively DNA primer-directed DNA polymerase; (iv) PabPCNA is required for PabpolD to perform efficient DNA synthesis but not PabpolB; (v) PabpolD, but not PabpolB, contains strand displacement activity (vii) in the presence of PabPCNA, however, both Pabpols D and B show strand displacement activity and (viii) we show that the direct interaction between PabpolD and PabPCNA is DNA-dependent. Our data imply that PabPolD might play an important role in DNA replication likely together with PabpolB, suggesting that archaea require two DNA polymerases at the replication fork.

Keywords: DNA replication, euryarchaea, gap filling, strand displacement, DNA polymerase, Okazaki fragments, PCNA. 


\section{Introduction}

Living organisms are faced with the tremendous task of maintaining the integrity of the genome. Enzymes called DNA polymerases (pols) are involved in highly sophisticated mechanisms for maintenance of the genome such as DNA replication, DNA recombination and DNA repair. Our knowlegde of DNA transactions in hyperthermophilic archaea was enlarged when the recent availability of the genomic sequences ${ }^{1}$ demonstrated the striking similarity between these extremophilic organisms and eukarya. Archaea, as the third kingdom of life, might serve as a useful model to understand DNA transactions in the more complex eukaryotic systems ${ }^{2}$. Biological studies are already yielding valuable data for studying the simpler archaeal DNA replication system. Indeed, a single replication origin in the euryarchaeal Pyrococcus abyssi (P. abyssi) was identified (ori $C)^{3}$ and bi-directional DNA replication was shown to be initiated ${ }^{4}$. In addition, short eukaryotic-like Okazaki fragments were detected in the two main archaeal phyla, P. abyssi and Sulfolobus acidocaldarius $(S$. acidocaldarius) ${ }^{5}$. Thus, archaea replicate their circular genome, as do bacteria i.e., much more rapidly than eukarya ${ }^{6}$, and they do this despite containing eukaryotic-like DNA replication proteins ${ }^{3}$. However, the situation became controversial within the crenarchaeota phyla. One study identified two origins of replication in the archaeon Sulfolobus solfataricus, (S. solfataricus $^{7,8}$, while another used a different technique to show that both $S$. solfataricus and $S$. acidocaldarius have three functional origins ${ }^{7,8}$. In eukarya, on the other hand, initiation of DNA replication takes place at multiple replication origins along the genome and this may correlate to the larger size of the eukaryal genome and the coordination of differential gene expression during development ${ }^{9}$.

Chromosomal DNA replication in eukaryotes require the three distinct Pol $\alpha$, Pol $\delta$ and Pol $\varepsilon$ (reviewed in refs ${ }^{10,11}$ ). Pol $\alpha$, with its associated DNA primase activity, is involved in the initiation step at the leading strand and in the repeated priming events required for 
replication of the lagging strand (reviewed in ref $^{12}$ ). However, Pol $\alpha /$ primase is only able to synthesize a short RNA-DNA primer of about 10 ribonucleotides and 20 deoxyribonucleotides, that is subsequently elongated by other pols. Pols $\delta$ and $\varepsilon$ are believed to be the two major replicative pols in metazoans, with Pol $\delta / \varepsilon$ acting on the leading strand and Pol $\delta$ at the lagging strand ${ }^{13}$. Given that eukaryotic DNA replication requires the coordinated action of at least three distinct pols at the replication fork, there must be a tight regulation to fulfill the efficient duplication of the genetic material. This mechanism involves polymerase switching from Pol $\alpha$ to Pol $\delta$ during the synthesis of each Okazaki fragment. The clamp PCNA and the clamp loader RF-C, are required for polymerase switching ${ }^{14}$. Since the closed PCNA ring cannot assemble onto a primed-template junction by itself, it requires the ATP-dependent loading by RF-C. Through physical interactions with the Pol $\delta$ and Pol $\varepsilon$, PCNA promotes rapid and processive DNA replication (reviewed in ${ }^{10}$ ). Maturation of Okazaki fragments, finally, requires the concerted action of several enzymes consisting of the removal of the RNA primer by Fen1, filling of the gap by Pol $\delta$ and sealing the resulting nick by DNA ligase $\mathrm{I}^{15}$.

Chromosomal DNA replication in bacteria appears to be simpler than in eukarya. In $E$. coli, DNA elongation involves the replicase, Pol III. Pol III is a complex molecular assemblies called holoenzyme ${ }^{16}$ composed of (i) the core enzyme $(\alpha, \varepsilon$ and $\theta)$ containing the polymerase and proofreading activities; (ii) a $\tau$-subunit that causes the core enzyme to dimerize; (iii) a $\beta$ processivity clamp that tethers the core enzymes to the chromosome and (iv) the five subunit clamp loader $(\gamma, \delta, \delta, \psi$ and $\chi)$ called $\gamma$-complex that allows to open and lock the ring clamp on the DNA ${ }^{16}$. Thus, in E. coli, there is one complex with two pols that replicates the leading as well as the lagging strand. Moreover, the two core enzymes are not pre-dedicated to one strand and can be interchanged ${ }^{17}$. The cycle of Okazaki fragments synthesis starts with the primase DnaG ${ }^{18}$, to which it remains stable bound through its 
association with the single-strand binding protein (SSB). Then, the $\gamma$-complex of Pol III displaces the primase from the primer-template junction upon binding SSB ${ }^{19}$. Subsequently, the lagging strand Pol III transits from the 3'-OH terminus of the newly completed Okazaki fragments to the new primer terminus, thus leading to DNA elongation. The cycle ends by removal of the previous RNA primer by RNase H, gap filling with Pol I and ligation by DNA ligase to create a duplex DNA ${ }^{6}$. However, little is known so far about the concerted action of Pol III and Pol I during Okazaki fragments maturation.

Archaea, the third domain of life, have an universally conserved replication machinery, including the sliding clamp PCNA, the clamp loader RF-C and (a) replicative pol (s). Even though several pols belonging to the B family $(\alpha, \delta, \varepsilon)$ have been implicated in chromosomal DNA replication in eukarya ${ }^{20}$, it is not clear whether members of B-type DNA polymerases are the replicative pols in archaea. According to the distribution of genes into the archaeal genomes, there is evidence for a family B pol to function solely during DNA replication in crenarchaeota and either a B- or D-type pol, or both in euryarchaeota ${ }^{21}$. Data obtained so far indicated that the family D pol (Pol D) might be a key-enzyme of DNA replication in euryarchaeota. Pol D is composed of a small subunit (DP1) which shows significant homologies with the small subunit of eukaryotic pols $\alpha, \delta$ and $\varepsilon^{22}$ and a large subunit (DP2) containing the polymerizing activity ${ }^{23}$. The pol D heterodimer possesses efficient DNA polymerizing and a 3'- $>5$ ' exonuclease (proofreading) activities ${ }^{24}$. Pol D from P. abyssi appears to be a heterodimer ${ }^{25}$ whereas Pol D from Pyrococcus horikoshii (PhopolD) is like Pol $\delta$ a heterotetramer. Moreover, its small subunit, DP1, physically interacts with PCNA ${ }^{26,27}$. Genetic analysis indicated that the two subunits of Pol D are clustered in an operon located adjacent to the replication origin in Pyrococcus ${ }^{3}$ containing essential genes for maintenance of the genome. Moreover, its ability to interact with multiple proteins involved in DNA replication, recombination and repair ${ }^{3,21,28}$ together with its newly 
characterised Mre11-like nuclease activity ${ }^{29}$ suggest that Pol D may participate, in addition of its proposed role in chromosomal replication, in DNA repair and recombination. However, due to the lack of genetic tools in archaea, it is not known whether both Pols B and D are essential for viability and what their exact functions are at the replication fork.

In this work we focus on the two known family B and D Pols of P. abyssi. We compared the recombinant Pols B and D by a variety of biochemical properties and our data indicated that PabPolD might play an important role in DNA replication likely together with PabpolB, suggesting that archaea might have two pols at the replication fork. 


\section{Results}

\section{Pab DNA polymerases B and D preferentially replicate synthetic DNA but not}

RNA. Our previous studies indicated that the newly identified family D pol from P. abyssi contains both polymerase and $3^{\prime}->5$ ' exonuclease activities as does the family $\mathrm{B}{ }^{25}$. Both enzymes are primer-directed DNA polymerases ${ }^{25}$. To gain further insight into the precise roles of the two pols, in a first approach, synthetic primed-templates different in composition were tested as outlined in Materials and Methods. When the homopolymeric $\operatorname{poly}(\mathrm{dA}) /$ Oligo $(\mathrm{dT})_{10: 1}$ or poly(dA)-oligo $(\mathrm{dT})_{40: 1}$ were tested, both Pabpols were with a moderate reduced activity in presence of poly(dA)-oligo(dT) $)_{40: 1}$. On the other hand both Pabpols were inactive with the poly(rA)/oligo(dT) at a both molar ratios of 40:1 and 10:1, suggesting lack of reverse transcriptase activity (Figure 1). Furthermore, both pols neither perform rNTPs incorporation nor de novo synthesis (data not shown).

\section{PabpolD binds preferentially primed-DNA templates and PabpolB binds single-} strand and primed-DNA template. The recognition of DNA structures by B- and D-type pols from archaea was never compared before. We therefore compared the two Pabpols for their DNA substrate binding abilities. Since Pabpols are potent pols and exonucleases in presence of divalent metal cations (24), EDTA was included in the binding reaction. To measure the difference of DNA binding abilities among the two pols, a titration analysis was performed in presence of several templates that can occur during DNA elongation. PabpolD was found to bind strongly to primed DNA (A2/B2) independently of $\mathrm{Mg}^{2+}$. The dose response was linear between 1-10 pmol and a single shifted species was observed (data not shown). In order to determine the specificity of PabpolD for the primed DNA (A2/B2, represented in Figure 2A) in the mobility shift assay, various nucleic acid competitors were 
added to the binding reaction (Figure 2B). Single-strand DNA and single-strand RNA competed inefficiently. An approximately 125-fold molar excess of single-strand DNA competitor was required to compete the binding of PabpolD away from the labeled primed DNA (Figure 2B, lanes 3-6). The single-strand RNA failed to compete even at a 125-fold excess (Figure 2B, lanes 17-20). RNA and DNA primed-templates, double-strand DNA competed efficiently with the labeled DNA primed-template. Double-strand DNA competed less efficiently (Figure 2B, lanes 7-10) than the DNA (Figure 2B, lanes 21-24) and RNA primed-templates (Figure 2B, lanes 11-14). These results suggest the requirement of a primed-template for strong binding of PabpolD. When, on the other hand, PabpolB was tested onto a primed-template, two different shifted species were observed (data not shown). Similarly to PabpolD, we found that PabpolB could bind the single-strand DNA independently of $\mathrm{Mg}^{2+}$ in a dose dependent manner. This dose response was linear between 5 and 15 pmol but only one single shift was observed (data not shown). Thus, we next measured the binding specificity of PabpolB to single-strand DNA by titrating derivatives of DNA structures (Figure 3A). Single-strand RNA and double-strand DNA could not compete efficiently the binding of PabpolB away from the labeled single-strand DNA (Figure 3B, lanes 17-24). Upon addition of unlabeled primed DNA templates, the shifted template was no longer detectable in the presence of a 25 -fold molar excess of competitor. The reduced binding of PabpolB was observed with DNA- and RNA primed-template competitors (Figure 3B, lanes 3-10). In summary, PabpolD binds preferentially primed-DNA templates and PabpolB binds single-strand as well as primed-DNA templates.

\section{PabPCNA can stimulate PabPolD and PabPolD can elongate an DNA and RNA}

primers. Next the abilities of both pols were tested on primed circular M13mp18 templates (Figure 4A) The results illustrated in Figure. 4B showed that PabpolB could incorporate 
dNTPs into M13mp18 to the same efficiency in presence of primers containing 3'-OH DNA ends (short DNA, DNA and hybrid RNA-DNA). Interestingly, PabpolB was inactive with an RNA primer (Figure 4B) and this even when higher amount of PabpolB were tested (data not shown). When these template-primer combinations (Figure 4A) were tested with PabpolD incorporation of dNTPs was observed independently with all four primers, including RNA. The amounts of nucleotides incorporated was moderately reduced in presence of a short DNA primer (Figure 4B). The DNA primer utilization by PabpolB was 3-fold higher than for PabpolD. Next, primer extension assays were carried out with 5'-end labeled primed M13mp18 DNA template (Figure 4A and 4C). Both Pabpols could elongate primers containing DNA 3'-OH ends. PabpolB accumulated full-length products (Figure 4C, lanes 2, 5 and 8) whereas PabpolD did stop after 3600 nucleotides (Figure 4C, lanes 3, 6 and 9) and longer incubation time did not increase the size of the products (data not shown). Moreover, the yield of full-size products was higher with PabpolB than with PabpolD, suggesting that the enzyme does not utilize the same amount of primers (Figure 4C, compare the lanes 3 and 6, 9 with the lanes 2, 5 and 8). These data correlate with the results of nucleotides incorporation observed in Figure 4B. Next the effect of PabPCNA (0.7 pmol) was investigated. Figure 4C shows that addition of PabPCNA stimulated the extension ability of PabpolD, since full-DNA synthesis could be observed (Figure 4C, compare lanes 15, 18 and 21 to lanes 3, 6 and 9) but, still, with lower efficiency compared to PabpolB alone (Figure 4C, lanes 14, 17 and 20). Increasing amounts of PabPCNA added into a PabpolD reaction did not affect the amount of the utilised primers (data not shown). As mentioned in Figure 4B, nucleotide incorporation in the presence of an RNA primer could only be observed with PabpolD. In order to detect significant RNA primer elongation, the length of single-strand template was shortened and the reaction products were visualised on a denaturing polyacrylamide gel. Replication was allowed to proceed with or without PabPCNA for both 
Pabpols as indicated (Figure 4D). Interestingly, PabpolD could elongate the RNA primer to the full-length even without PabPCNA. Moreover, the inability of PabpolB for RNA primer extension was confirmed and that could not be overcome by the addition of PabPCNA. These data demonstrate that the family D pol is an DNA and an RNA primer-directed pol whereas the family B pol can only use DNA primers.

PabpolD, but not PabpolB, can perform strand displacement DNA synthesis. Since eukaryotic pols $\beta$ and $\delta$ can perform strand displacement synthesis ${ }^{30,31}$, we next tested Pabpols for these properties. A single-strand circular M13mp18 with a defined gap of 25-nt containing either an RNA or an DNA downstream primer (Figure 5A) was used. Elongation was monitored by incubating Pabpols at a 3-fold excess over the template. Gap filling synthesis results in a 57-nt fragment and strand displacement activity gives longer products up to 87-nt. PabpolD could displace the DNA downstream primer after completion of the gap (Figure 5B, lane 3). However, an accumulation of 57-base pair products occurred in presence of an RNA downstream primer (Figure 5B, lane 6). When, on the other hand, PabpolB was tested DNA synthesis proceeded until the 5'-end of the DNA downstream primer was reached corresponding to the 57-nt elongated product (Figure 5B, lane 9). No displacement of the DNA downstream fragment by PabpolB even at longer incubation times could be detected and an increase of the dNTPs concentration had no effect (data not shown). Finally, an RNA downstream primer prevented the precise gap filling by PabpolB (Figure 5B, lane 12).

The gap size does neither influence the gap filling nor strand displacement DNA synthesis by the Pabpols $B$ and $D$. We next addressed whether the gap size affects the Pabpols. Gap sizes of 1, 10, 25, 50 and 100 nucleotides were prepared as outlined in Table 1 and Figure 6A. PabpolD was able to fill gaps of all sizes tested and was able to displace 
efficiently the DNA downstream primer and this independently of the gap size (Figure 6B, lanes 3-8). Again, when the downstream DNA primer was replaced by an RNA primer, strand displacement activity of PabpolD was prevented (Figure 6B, lanes 9-14). PabpolB, on the other hand, was able to fill the gap, but no strand displacement activity was observed even by decreasing the gap size (Figure 6C, lanes 3-8). DNA primer elongation was severely reduced in presence of gapped template containing an RNA downstream primer (Figure 6C, lanes 914). These data indicated that, irrespectively of the gap size, only PabpolD can perform strand displacement synthesis only in the presence of DNA.

The strand displacement synthesis of Pabpols D and B are stimulated by PabPCNA in presence of a defined downstream primer-template. PabPCNA was next tested for its effect on gap filling reaction and on strand displacement synthesis by Pabpols D and B. To address this question, the dNTP concentration was lowered 2-fold and M13mp18 with a defined gap of 25-nucleotides containing either an RNA or an DNA downstream primer were used (Figure 7A). Under these reaction conditions, strand displacement activity by PabpolD on an DNA oligonucleotide was stimulated by PabPCNA (Figure 7B, lanes 4-5). Interestingly, PabpolD could displace the RNA primer in the presence of PabPCNA (Figure 7B, lanes 6-7). Moreover, when PabPCNA was added to PabpolB, gap filling was now seen until the 5'-end of the downstream DNA primer was reached and the strand displacement activity was enhanced (Figure 7C, lanes 4-5). No effect of PabPCNA onto PabpolB activity in presence of the RNA downstream primer was observed (Figure 7C, lanes 6-7). In summary, PabPCNA can enhance the strand displacement synthesis of both PabpolD and B.

The physical interaction between Pabpols and PabPCNA is DNA-dependent. Since we demonstrated that $\mathrm{PabPCNA}$ is required to stimulate primer elongation and strand 
displacement synthesis by Pabpols D and B (Figures 4C and 7B-7C), we therefore investigated whether PabPCNA can physically interact with the two Pabpols using the SPR assay. No direct interaction between PabPCNA and either PabpolD (Figure 8A, curve 1) or PabpolB (Figure 8B, curve 1) was seen. This result was similarly found in a negative pulldown assay (data not shown). However, when an DNA primed-template was immobilised onto the sensor chip, both Pabpols were able to bind the immobilised primed-template (Figure 8A and B, curves 2). When PabPCNA and Pabpols were added sequentially over the primedtemplate sensor chip, a stronger level of binding could be observed (Figure 8A and B, curves 3), suggesting that PabPCNA promotes the association of Pabpols with the PCNA/DNA complex. Taken together, we assume that the physical interactions between Pabpols D and B and PabPCNA are DNA-dependent. 


\section{Discussion}

Archaea, the third domain of life, are fascinating microorganisms since they show a bacterial-like DNA replication with its circular chromosome, a high DNA replication speed and a bi-directional replication. On the other hand they use eukaryal-like DNA replication proteins ${ }^{32}$. Compared to eukaryotes, archaeal replication requires structurally simpler DNA replication complexes. They have evolved differently to initiate duplication of their genome ${ }^{3 \text {, }}$ $5,7,8$. Here we focused on the two pols D and B from the hyperthermophilic euryarchaeota Pyrococcus abyssi. The family D and B pols are bona fide DNA polymerases and require a primer to initiate DNA synthesis (Figure 1). PabpolD preferentially binds primed-templates (Figure 2B) consistent with its ability to extend primers independently of their composition. PabpolD initiated DNA synthesis in presence of various primed-templates but to a lower efficiency than PabpolB. PabPCNA could stimulate DNA synthesis of full-length products (Figure 4C). Therefore, PabPCNA is likely required for PabpolD to perform efficient DNA synthesis. Moreover, the length of single-strand regions seems to be a pre-requisite in order to detect the RNA primer elongation by PabpolD, thus restricting the size of the newly extended product (Figure 4D). In contrast, PabpolB could discriminate between an RNA or DNA primer and could only extend an DNA primed-template (Figure 4B and C). When PabpolB was tested in a gel shift competition assay, binding was observed to single-strand DNA with primed-templates as good competitors (Figure 3B). This is not surprising because it involves the already known properties of archaeal family-B ${ }^{33}$. However, the observation that an RNA primed-template could compete the single-strand binding of PabpolB with only a 25-fold molar excess was unexpected, taking into account that PabpolB could not elongate an RNA primer and this even in the presence of PabPCNA (Figure 4C) and/or a short single-strand region (Figure 4D). Therefore, PabpolB can interact with an RNA-primed template. Hence, 
this explanation would corroborate with the identification of an RNA-binding domain at the N-terminus of the family B pols ${ }^{34}$.

PabpolD can efficiently perform strand displacement DNA synthesis when the downstream nucleic acid was DNA but not RNA (Figure 5B) and these properties were unchanged by varying the size of the gap (Figure 6B). On the other hand, PabpolB did not show displacement of DNA or RNA (Figure 5B). In addition, an RNA downstream primer prevented the precise gap filling by PabpolB under all conditions tested (Figure 6C). PabPCNA could stimulate strand displacement DNA activity of PabpolD (Figure 7B). Stimulation of the strand displacement activity of PabpolB was only detected for DNA when PabPCNA was added (Figure 7C).

The results presented in this paper suggest that Pabpols D and B might both be involved in DNA replication. Indeed, a replicase like human Pol $\delta$ is known to perform strand displacement DNA synthesis of the pre-existing downstream Okazaki fragment thus resulting in an intermediate flap structure that is the target of the subsequent concerted action of Fen1, PCNA and DNA ligase $\mathrm{I}^{30}$. By analogy with the eukaryotic mechanisms, PabpolD would appear to be a candidate to carry out the completion of Okazaki fragments and to create PCNA-dependent displacement of the encountering RNA-DNA primer. Our data together with those published so far let us to propose a model for archaeal replication: A primase is recruited to the replication origin to initiate synthesis of a short RNA primer ${ }^{35,36}$. This is followed by the incorporation of a short stretch of DNA by Pol D at both the lagging and leading strands. Subsequently, the RNA-DNA primer is further elongated by the replicases, in which we propose that one enzyme is active on the leading strand and the other on the lagging strand. Pol B might be the candidate to replicate the leading strand while Pol D could synthesize the lagging strand. Completion of the Okazaki fragments by Pol D would lead to 
the strand displacement of the RNA-DNA primer, thus targeting maturation enzymes such as RNaseH2, Fen1 and DNA ligase to generate an intact DNA strand ${ }^{32}$.

Abbreviations used: Pab, Pyrococcus abyssi; dNTP, deoxyriboNucleosideTriPhosphate; nt, nucleotide; pol, polymerase; RF-C, Replication Factor C; PCNA, Proliferating Cell Nuclear Antigen; Fen1, Flap endonuclease 1.

\section{Acknowledgements}

This work was supported by the European committee through the REPBIOTECH program (Contract Number QLK3-CT-2002-02071). We are grateful to P. Trouvé for giving access to the BIAcore X apparatus (INSERM U.613, Molecular genetics and genetic epidemiology, Brest, France). U. Hübscher is supported by the Kanton of Zürich. We especially thank I.V. Shevelev (Zurich, Switzerland) for stimulating discussions. 


\section{Materials and Methods}

\section{Chemicals and Enzymes}

$\left[{ }^{3} \mathrm{H}\right] \mathrm{dTTP}(1.5 \mathrm{Ci} / \mathrm{mmol}),\left[\gamma_{-}{ }^{32} \mathrm{P}\right] \mathrm{ATP}(3000 \mathrm{Ci} / \mathrm{mmol})$, and $\left[\alpha-{ }^{32} \mathrm{P}\right] \mathrm{dATP}(3000$ $\mathrm{Ci} / \mathrm{mmol})$ were from Amersham Biosciences. Unlabeled dNTPs, poly(dA), poly(rA) and Oligo(dT) $)_{12-18}$ were from Roche Molecular Biochemicals. Single-strand circular (ssc) M13mp18 was purchased from Amersham Biosciences. T4 polynucleotide kinase was from New England Biolabs. PabpolB and PabpolD were cloned, expressed and purified as described earlier ${ }^{25}$. Recombinant PabPCNA was produced in E. coli and purified to homogeneity as described ${ }^{37} .1$ unit of Pabpols activity corresponds to the incorporation of 1 nmol of total dTMP into acid precipitable material per min at $50^{\circ} \mathrm{C}$ in a standard assay containing $0.5 \mu \mathrm{g}$ (as nucleotides) of poly $(\mathrm{dA}) /$ oligo(dT) $)_{10: 1}$. Whatman was the supplier of the GF/C filters. All other reagents were of analytical grade and purchased from Sigma-Aldrich and Fluka.

\section{Nucleic acid substrates}

Oligonucleotides used to prepare the substrates for primer extension and gap filling assays were synthesised and purified by Eurogentec (Belgium). When appropriate, labeling at the 5 '-end was performed using $\left[\gamma^{32} \mathrm{P}\right] \mathrm{ATP}$ and T4 polynucleotide kinase. Free $\left[\gamma^{32} \mathrm{P}\right] \mathrm{ATP}$ was removed on Microspin ${ }^{\mathrm{TM}}$ G-25 columns. The gapped and primed DNA templates were prepared by annealing oligonucleotides and M13mp18 template in a 3:1 molar ratio in $30 \mathrm{mM}$ Tris- $\mathrm{HCl}(\mathrm{pH} 7.5), 100 \mathrm{mM} \mathrm{NaCl}, 1 \mathrm{mM}$ EDTA. The mixture was heated to $75^{\circ} \mathrm{C}$ and slowly cooled down to room temperature. The DNA templates for the short single-strand RNA primer extension and the mobility shift competition assays were prepared according to the 
same protocol with the complementary oligonucleotides mixed in mol:mol ratio. The sequences of the different oligonucleotides used in this work are listed in Table 1.

\section{DNA polymerase assays}

Pol activities on poly $(\mathrm{dA}) / \mathrm{oligo}(\mathrm{dT})_{40: 1}$, poly $(\mathrm{dA}) / \mathrm{oligo}(\mathrm{dT})_{10: 1}$, poly(rA)/oligo $(\mathrm{dT})_{40: 1}$ and poly(rA)/oligo(dT) $)_{10: 1}$, were dertermined in a final volume of $20 \mu \mathrm{l}$ containing the following components : $0.5 \mu \mathrm{g}$ of template/primer, $5 \mu \mathrm{M}\left[{ }^{3} \mathrm{H}\right] \mathrm{dTTP}(5 \mathrm{Ci} / \mathrm{mmol}), 50 \mu \mathrm{M}$ of unlabeled dNTP and 0.2 pmol of Pabpols to be tested in their respective buffer: (i) for PabpolD : 20 mM Bis-Tris (pH 6.5), $1 \mathrm{mM}$ dithiothreitol (DTT), $0.4 \mathrm{mg} / \mathrm{ml}$ of bovine serum albumin (BSA), $10 \mathrm{mM} \mathrm{MgCl}_{2}$; (ii) for PabpolB : $50 \mathrm{mM}$ Tris-HCl (pH 8.8), 1 mM DTT, 0.4 $\mathrm{mg} / \mathrm{ml} \mathrm{BSA}, 2 \mathrm{mM} \mathrm{MgCl} 2,10 \mathrm{mM} \mathrm{KCl}$. Reactions were incubated at $50^{\circ} \mathrm{C}$ for 30 minutes and stopped on ice for 5 minutes. The DNA products were precipitated with $10 \%(\mathrm{w} / \mathrm{v})$ TCA and insoluble radioactive material was determined by scintillation counting. 


\section{Primer extension on primed sscM13mp18 DNA}

Acid precipitable assay. Primer extension was performed in a final volume of $20 \mu 1$ containing the following components : (i) for PabpolD : $20 \mathrm{mM}$ Bis-Tris (pH 6.5), $1 \mathrm{mM}$ dithiothreitol (DTT), $0.4 \mathrm{mg} / \mathrm{ml}$ of bovine serum albumin (BSA), $10 \mathrm{mM} \mathrm{MgCl}$, $100 \mathrm{ng}$ of different primed DNA templates, $200 \mu \mathrm{M}$ of unlabeled dNTP, $20 \mu \mathrm{M}\left[{ }^{3} \mathrm{H}\right] \mathrm{dTTP}$ and enzyme to be tested ; (ii) for PabpolB : $50 \mathrm{mM}$ Tris- $\mathrm{HCl}(\mathrm{pH} 8.8), 1 \mathrm{mM}$ DTT, $0.4 \mathrm{mg} / \mathrm{ml} \mathrm{BSA}, 2$ $\mathrm{mM} \mathrm{MgCl} 2,10 \mathrm{mM} \mathrm{KCl} ; 100 \mathrm{ng}$ of different primed DNA templates, $200 \mu \mathrm{M}$ of unlabeled dNTP, $20 \mu \mathrm{M}\left[{ }^{3} \mathrm{H}\right] \mathrm{dTTP}$ and enzymes to be tested. All reactions were incubated for 30 minutes at $55^{\circ} \mathrm{C}$ and the DNA was precipitated with $10 \%$ trichloroacetic acid (TCA). Insoluble radioactive material was determined by scintillation counting as described ${ }^{38}$.

Product analysis. The composition of buffers, DTT, BSA, and $\mathrm{MgCl}_{2}$ for PabpolD and PabpolB were identical to the acid precipitable assay. The final volume of $15 \mu 1$ contained unlabeled $200 \mu \mathrm{M}$ dNTP, 100 ng of different primed DNA templates and 0.2 pmol of Pabpols with or without 0.7 pmol PabPCNA, as indicated in the respective Figure legends. The reactions were incubated for 30 minutes at $55^{\circ} \mathrm{C}$, samples were quenched on ice by adding $30 \mathrm{mM} \mathrm{NaOH}, 1 \mathrm{mM}$ EDTA and the products were separated on a $0.8 \%(\mathrm{w} / \mathrm{v})$ denaturing alkaline agarose gel and analysed by autoradiography.

\section{RNA primer extension on a single strand linear DNA template}

This assay was performed in a final volume of $15 \mu$ containing: 0.25 pmol of labeled template, $200 \mu \mathrm{M}$ dNTP and $0.2 \mathrm{pmol}$ of Pabpols in their respective buffer, DTT, BSA, and $\mathrm{MgCl}_{2}$ conditions (see above) either in the absence or in the presence of PabPCNA (0.7 pmol). The reaction was carried out at $55^{\circ} \mathrm{C}$ for 30 minutes and quenched on ice for 5 minutes and stopped by addition of the $2.5 \mathrm{x}$ stop buffer $(95 \%$ (v/v) formamid, $20 \mathrm{mM}$ EDTA, $0.05 \%$ 
$(\mathrm{w} / \mathrm{v})$ bromophenol blue and $0.05 \%(\mathrm{w} / \mathrm{v})$ xylene cyanol). Products were separated on $15 \%$ denaturing polyacrylamide gels and visualised by autoradiography.

\section{Gap filling assays}

The standard reaction mixture $(15 \mu \mathrm{l})$ and the respective buffer, DTT, BSA, and $\mathrm{MgCl}_{2}$ conditions (see above) for PabpolB and PabpolD were identical to the primer extension assay. For varying the size of the gap, the appropriate DNA upstream primer was mixed with the downstream RNA or DNA primer and the sscM13mp18 DNA template. The reaction included unlabeled dNTPs $(200 \mu \mathrm{M}), 0.2$ pmol of Pabpols and 0.07 pmol of gapped templates as indicated in the respective Figure legends. For PabPCNA stimulation of Pabpols, the dNTP concentration was lowered to $100 \mu \mathrm{M}$. All reactions were carried out at $60^{\circ} \mathrm{C}$ for 30 min and stopped by adding denaturing gel loading buffer (95\% (v/v) formamid, 10 mM EDTA, $0.05 \%$ bromophenol blue, $0.05 \%$ xylene cyanol). The products were resolved by electrophoresis on a denaturing resolution gel and by autoradiography.

\section{Electrophoresis mobility shift assay (EMSA)}

Binding reactions were carried out in a total volume of $20 \mu 1$ containing: $50 \mathrm{mM}$ Tris$\mathrm{HCl}$ (pH 8.0), $20 \mathrm{mM} \mathrm{NaCl}, 5 \mathrm{mM}$ EDTA, $50 \mu \mathrm{g} / \mathrm{ml} \mathrm{BSA,} \mathrm{4 \%} \mathrm{Ficoll,} 0.5 \mathrm{pmol}$ of labeled oligonucleotide probe, and the indicated amount of Pabpols. Following a 20-min incubation at $25^{\circ} \mathrm{C}$, the reactions were loaded onto a $5 \%$ polyacrylamide gel containing $0.5 \mathrm{x}$ TBE and run first at $50 \mathrm{~V}$ for 45 minutes and then at $100 \mathrm{~V}$ for 90 minutes. The gels were exposed to a screen and the bands were visualised by phosphoimager (Biorad). When more than one oligonucleotide was part of a competitor oligonucleotide complex (e.g. A1/B2 in the doublestrand structure), the number of pmol in the figure corresponds only to the oligonucleotide 
$\mathrm{B} 2$, and in order to constitute the complete competitor structure the other oligonucleotides listed in Table 1 was added at an equimolar ratio to B2.

\section{Surface Plasmon Resonance (SPR) experiments}

SPR analysis were performed in a BIAcore X apparatus (BIAcore, Uppsala Sweden) using either a DNA or a PCNA sensor chip. When a DNA chip was used, a biotinylated template B2 hybridised to the primer A2 (Table 1) was attached to the chip (SA sensor chip, BIAcore) via the streptavidin-biotin linkage. Approximately 200 RU (Resonance Unit) of template were immobilised. The interaction between Pabpols and the complex DNA/PCNA were monitored as followed: PabPCNA (200 nM) was injected over the DNA chip and 1.4 pmol of Pabpols was supplemented 30 seconds after injection. When a PCNA chip was used, approximately $150 \mathrm{RU}$ of PabPCNA were covalently fixed on the surface of a dextran chip (CM5) by an amine coupling method according to the manufacturer's instructions. In all experiments, the interactions were monitored at $25^{\circ} \mathrm{C}$ at a flow rate of $30 \mu \mathrm{l} / \mathrm{min}$ in HBS-P buffer (10 mM HEPES, pH 7.4, $150 \mathrm{mM} \mathrm{NaCl,} \mathrm{0.005 \%} \mathrm{(v/v)} \mathrm{P20).}$ 


\section{Figure Legends}

Figure 1. Pab DNA polymerases preferentially replicate synthetic DNA but not RNA. The assays were performed as outlined in Materials and Methods and included $0.5 \mu \mathrm{g}$ of $\operatorname{poly}(\mathrm{dA}) / \mathrm{oligo}(\mathrm{dT})$ or poly(rA)/oligo(dT) in a ratio of template :primer of either $(10: 1)$ or $(40: 1)$. The activities of PabpolD and PabpolB were each compared to those of $\operatorname{poly}(\mathrm{dA}) /$ oligo(dT) (10:1).

Figure 2. PabpolD specifically binds primed DNA. A, Schematic template bound. B, Gel shift competition reactions were carried out as described under Materials and Methods. Each reaction contained $10 \mathrm{pmol}$ of purified PabpolD and the indicated amount of the following nucleic acid competitor : lanes 1 and 2, no competitor; lanes 3-6, B2 ; lanes 7-10, A1/B2 ; lanes 11-14, C1/B2 ; lanes 15-16, no competitor ; lanes 17-20, C1; lanes 21-24, A2/B2. The positions of free and complexes labeled templates are indicated on the left. The templates are represented in Table 1.

Figure 3. PabpolB binds single-strand and primed-DNA templates. A, Template used in this study. B, Binding reactions were carried out as described under Materials and Methods. Each reaction contained 15 pmol of purified PabpolB and the indicated amounts of the following nucleic acid competitors (see Table 1 for details): lanes 1 and 2, no competitor; lanes 3-6, A2/B2; lanes 7-10, C1/B2; lanes 11-12, no competitor; lanes 13-16, B2 ; lanes 17-20, C1; lanes 21-24, A1/B2. The positions of free and complexes labeled templates are indicated on the left. 


\section{Figure 4. PabPCNA can stimulate PabPolD and PabPolD can elongate DNA and RNA}

primers. A, the different primers hybridised to the M13mp18 template were : RNAp, DNAp, short DNA and RNA-DNA hybrid primer. $100 \mathrm{ng}$ of these four primed-M13mp18 DNA templates (base ratio 3:1) were tested in the respective polymerase reactions for PabpolD and PabpolB at $55^{\circ} \mathrm{C}$ for 30 minutes with 0.2 pmol of each Pabpols. B, dNTP incorporation into the four different primed-templates were tested by acid precipitation. C, primer extension assays were performed with the 5'-labeled primers hybridised to the M13mp18 template (100 ng) in the presence or absence of PabPCNA (0.7 pmol) and 0.2 pmol of Pabpols as indicated. The extended products were separated on a $0.8 \%(\mathrm{w} / \mathrm{v})$ denaturing alkaline agarose gel. D, RNA primer elongation was measured on a short single-strand linear DNA template in the respective polymerase reactions for PabpolD and PabpolB with or without PabPCNA and analysed by a $15 \%$ denaturing polyacrylamide gel as outlined in Materials and Methods.

Figure 5. PabpolD, but not PabpolB, can perform strand displacement DNA synthesis. A, the DNA template used was single-strand M13mp18 with a 5'-labeled upstream DNA and a downstream DNA or RNA oligonucleotide, respectively. The gap was 25-nt. The reaction was performed at $60^{\circ} \mathrm{C}$ for 30 minutes as described in Materials and Methods with 0.2 pmol Pabpols, $200 \mu \mathrm{M}$ dNTP and 0.07 pmol of 25-nt gapped M13mp18 DNA templates. Samples were analysed on a $15 \%$ denaturing polyacrylamide gel and by autoradiography. B, Gap filling and strand displacement activities by PabpolD (lanes 1-6) and PabpolB (lanes 7-12). Lanes 1, 4, 7 and 10 were the control without enzyme. Lanes 2, 5, 8 and 11 were time zero. Lanes 3, 6, 9 and 12 were 30-min incubation time.

Figure 6. The gap size does neither influence the gap filling nor strand displacement DNA synthesis by the Pabpols B and D. A, the DNA template used in the study was a 
M13mp18 with a downstream DNA or RNA primer and different 5'-labeled upstream DNA oligonucleotides in order to create the appropriate gap size. Reactions were performed as described in Figure 5. B, gap filling and strand displacement synthesis by PabpolD (0.2 pmol) were tested at various gap sizes in the presence of DNA (lanes 3-8) or RNA (9-14). C, gap filling and strand displacement synthesis by PabpolB (0.2 pmol) were tested at various gap sizes in the presence of DNA (lanes 3-8) or RNA (9-14).

Figure 7. The strand displacement synthesis of Pabpols D and B are both stimulated by PabPCNA in presence of a defined downstream primer-template. A, the template used is the 25-nt gapped M13mp18 DNA indicated in the Figure 5. B, 0.2 pmol of PabpolD were incubated alone or in the presence of PabPCNA ( 0.7 pmol). C, 0.2 pmol of PabpolB were incubated alone or in the presence of PabPCNA ( 0.7 pmol). Lanes 1 and 2 are the DNA markers corresponding to the 57-mer (filled gap) and 87-mer (displaced strand). Lanes 3-7 contained the primers, the pols and PCNA as indicated above the gel. Reactions were performed at $60^{\circ} \mathrm{C}$ for 30 minutes with 0.07 pmol of template and $100 \mu \mathrm{M}$ of dNTP as outlined in Materials and Methods. The products were resolved by a $15 \%$ denaturing polyacrylamide gel and revealed by autoradiography

Figure 8. The physical interaction between Pabpols and PabPCNA is DNA-dependent. A, Curve 1: PabpolD (1.4 pmol) was injected over the immobilised PabPCNA. Curve 2: control injection of PabpolD binding to the primed-template (A2/B2). Curve 3: PabPCNA and PabpolD were sequentially added over a primed-template (A2/B2) sensor chip. B The PabpolB experiment were performed as described for PabpolD. , Curve 1: PabpolB injection over the immobilised PabPCNA. Curve 2: Control injection of PabpolB binding to the primed-template. Curve 3: PabPCNA and PabpolB were sequentially added over the primed- 
template sensor chip. The background resulting from the injection buffer alone was subtracted in each case from the data before plotting. 


\section{References}

1. $\quad$ www.ncbi.nlm.nih.gov/Entrez/Genome/org.html.

2. Bohlke, K., Pisani, F. M., Rossi, M. \& Antranikian, G. (2002). Archaeal DNA replication: spotlight on a rapidly moving field. Extremophiles 6, 1-14.

3. Myllykallio, H., Lopez, P., Lopez-Garcia, P., Heilig, R., Saurin, W., Zivanovic, Y., Philippe, H. \& Forterre, P. (2000). Bacterial mode of replication with eukaryotic-like machinery in a hyperthermophilic archaeon. Science 288, 2212-5.

4. Matsunaga, F., Forterre, P., Ishino, Y. \& Myllykallio, H. (2001). In vivo interactions of archaeal Cdc6/Orc1 and minichromosome maintenance proteins with the replication origin. Proc Natl Acad Sci US A 98, 11152-7.

5. Matsunaga, F., Norais, C., Forterre, P. \& Myllykallio, H. (2003). Identification of short 'eukaryotic' Okazaki fragments synthesized from a prokaryotic replication origin. EMBO Rep 4, 154-8.

6. Kornberg, A. \& Baker, T. A. (1992). Replication mechanisms and operations. In DNA replication (Kornberg, A. \& Baker, T. A., eds.), pp. 471-510. Freeman, New York.

7. Robinson, N. P., Dionne, I., Lundgren, M., Marsh, V. L., Bernander, R. \& Bell, S. D. (2004). Identification of two origins of replication in the single chromosome of the archaeon Sulfolobus solfataricus. Cell 116, 25-38.

8. Lundgren, M., Andersson, A., Chen, L., Nilsson, P. \& Bernander, R. (2004). Three replication origins in Sulfolobus species: synchronous initiation of chromosome replication and asynchronous termination. Proc Natl Acad Sci U S A 101, 7046-51.

9. Boulikas, T. (1996). Common structural features of replication origins in all life forms. J Cell Biochem 60, 297-316. 
10. Hubscher, U., Maga, G. \& Spadari, S. (2002). Eukaryotic DNA polymerases. Annu Rev Biochem 71, 133-63.

11. Toueille, M. \& Hubscher, U. (2004). Regulation of the DNA replication fork: a way to fight genomic instability. Chromosoma 113, 113-25.

12. Muzi-Falconi, M., Giannattasio, M., Foiani, M. \& Plevani, P. (2003). The DNA polymerase alpha-primase complex: multiple functions and interactions. ScientificWorldJournal 3, 21-33.

13. Fukui, T., Yamauchi, K., Muroya, T., Akiyama, M., Maki, H., Sugino, A. \& Waga, S. (2004). Distinct roles of DNA polymerases delta and epsilon at the replication fork in Xenopus egg extracts. Genes Cells 9, 179-91.

14. Maga, G., Stucki, M., Spadari, S. \& Hubscher, U. (2000). DNA polymerase switching: I. Replication factor C displaces DNA polymerase alpha prior to PCNA loading. $J$ Mol Biol 295, 791-801.

15. Waga, S. \& Stillman, B. (1998). The DNA replication fork in eukaryotic cells. Annu Rev Biochem 67, 721-51.

16. Kornberg, A. (1988). DNA replication. J Biol Chem 263, 1-4.

17. Yuzhakov, A., Turner, J. \& O'Donnell, M. (1996). Replisome assembly reveals the basis for asymmetric function in leading and lagging strand replication. Cell 86, 87786.

18. Kitani, T., Yoda, K., Ogawa, T. \& Okazaki, T. (1985). Evidence that discontinuous DNA replication in Escherichia coli is primed by approximately 10 to 12 residues of RNA starting with a purine. J Mol Biol 184, 45-52.

19. Yuzhakov, A., Kelman, Z. \& O'Donnell, M. (1999). Trading places on DNA--a threepoint switch underlies primer handoff from primase to the replicative DNA polymerase. Cell 96, 153-63. 
20. Hubscher, U., Nasheuer, H. P. \& Syvaoja, J. E. (2000). Eukaryotic DNA polymerases, a growing family. Trends Biochem Sci 25, 143-7.

21. Cann, I. K. \& Ishino, Y. (1999). Archaeal DNA replication: identifying the pieces to solve a puzzle. Genetics 152, 1249-67.

22. Aravind, L. \& Koonin, E. V. (1998). Phosphoesterase domains associated with DNA polymerases of diverse origins. Nucleic Acids Res 26, 3746-52.

23. Shen, Y., Musti, K., Hiramoto, M., Kikuchi, H., Kawarabayashi, Y. \& Matsui, I. (2001). Invariant Asp-1122 and Asp-1124 are essential residues for polymerization catalysis of family D DNA polymerase from Pyrococcus horikoshii. J Biol Chem 276, 27376-83.

24. Tang, X. F., Shen, Y., Matsui, E. \& Matsui, I. (2004). Domain Topology of the DNA Polymerase D Complex from a Hyperthermophilic Archaeon Pyrococcus horikoshii. Biochemistry 43, 11818-27.

25. Gueguen, Y., Rolland, J. L., Lecompte, O., Azam, P., Le Romancer, G., Flament, D., Raffin, J. P. \& Dietrich, J. (2001). Characterization of two DNA polymerases from the hyperthermophilic euryarchaeon Pyrococcus abyssi. Eur J Biochem 268, 5961-9.

26. Shen, Y., Tang, X. F. \& Matsui, I. (2003). Subunit interaction and regulation of activity through terminal domains of the family D DNA polymerase from Pyrococcus horikoshii. J Biol Chem 278, 21247-57.

27. Shen, Y., Tang, X. F., Matsui, E. \& Matsui, I. (2004). Subunit interaction and regulation of activity through terminal domains of the family D DNA polymerase from Pyrococcus horikoshii. Biochem Soc Trans 32, 245-9.

28. Hayashi, I., Morikawa, K. \& Ishino, Y. (1999). Specific interaction between DNA polymerase II (PolD) and RadB, a Rad51/Dmc1 homolog, in Pyrococcus furiosus. Nucleic Acids Res 27, 4695-702. 
29. Shen, Y., Tang, X. F., Yokoyama, H., Matsui, E. \& Matsui, I. (2004). A 21-amino acid peptide from the cysteine cluster II of the family D DNA polymerase from Pyrococcus horikoshii stimulates its nuclease activity which is Mre11-like and prefers manganese ion as the cofactor. Nucleic Acids Res 32, 158-68.

30. Maga, G., Villani, G., Tillement, V., Stucki, M., Locatelli, G. A., Frouin, I., Spadari, S. \& Hubscher, U. (2001). Okazaki fragment processing: modulation of the strand displacement activity of DNA polymerase delta by the concerted action of replication protein A, proliferating cell nuclear antigen, and flap endonuclease-1. Proc Natl Acad Sci US A 98, 14298-303.

31. Podlutsky, A. J., Dianova, II, Podust, V. N., Bohr, V. A. \& Dianov, G. L. (2001). Human DNA polymerase beta initiates DNA synthesis during long-patch repair of reduced AP sites in DNA. Embo $J$ 20, 1477-82.

32. Grabowski, B. \& Kelman, Z. (2003). Archeal DNA replication: eukaryal proteins in a bacterial context. Annu Rev Microbiol 57, 487-516.

33. Lou, H., Duan, Z., Sun, T. \& Huang, L. (2004). Cleavage of double-stranded DNA by the intrinsic $3^{\prime}-5^{\prime}$ exonuclease activity of DNA polymerase B1 from the hyperthermophilic archaeon Sulfolobus solfataricus at high temperature. FEMS Microbiol Lett 231, 111-7.

34. Zhao, Y., Jeruzalmi, D., Moarefi, I., Leighton, L., Lasken, R. \& Kuriyan, J. (1999). Crystal structure of an archaebacterial DNA polymerase. Structure Fold Des 7, 118999.

35. Lao-Sirieix, S. H. \& Bell, S. D. (2004). The Heterodimeric Primase of the Hyperthermophilic Archaeon Sulfolobus solfataricus Possesses DNA and RNA Primase, Polymerase and 3'-terminal Nucleotidyl Transferase Activities. J Mol Biol $344,1251-63$ 
36. De Falco, M., Fusco, A., De Felice, M., Rossi, M. \& Pisani, F. M. (2004). The DNA primase of Sulfolobus solfataricus is activated by substrates containing a thymine-rich bubble and has a 3'-terminal nucleotidyl-transferase activity. Nucleic Acids Res 32, 5223-30.

37. Henneke, G., Gueguen, Y., Flament, D., Azam, P., Querellou, J., Dietrich, J., Hubscher, U. \& Raffin, J. P. (2002). Replication factor C from the hyperthermophilic archaeon Pyrococcus abyssi does not need ATP hydrolysis for clamp-loading and contains a functionally conserved RFC PCNA-binding domain. J Mol Biol 323, 795810.

38. Hubscher, U. \& Kornberg, A. (1979). The delta subunit of Escherichia coli DNA polymerase III holoenzyme is the dnaX gene product. Proc Natl Acad Sci US A 76, 6284-8. 


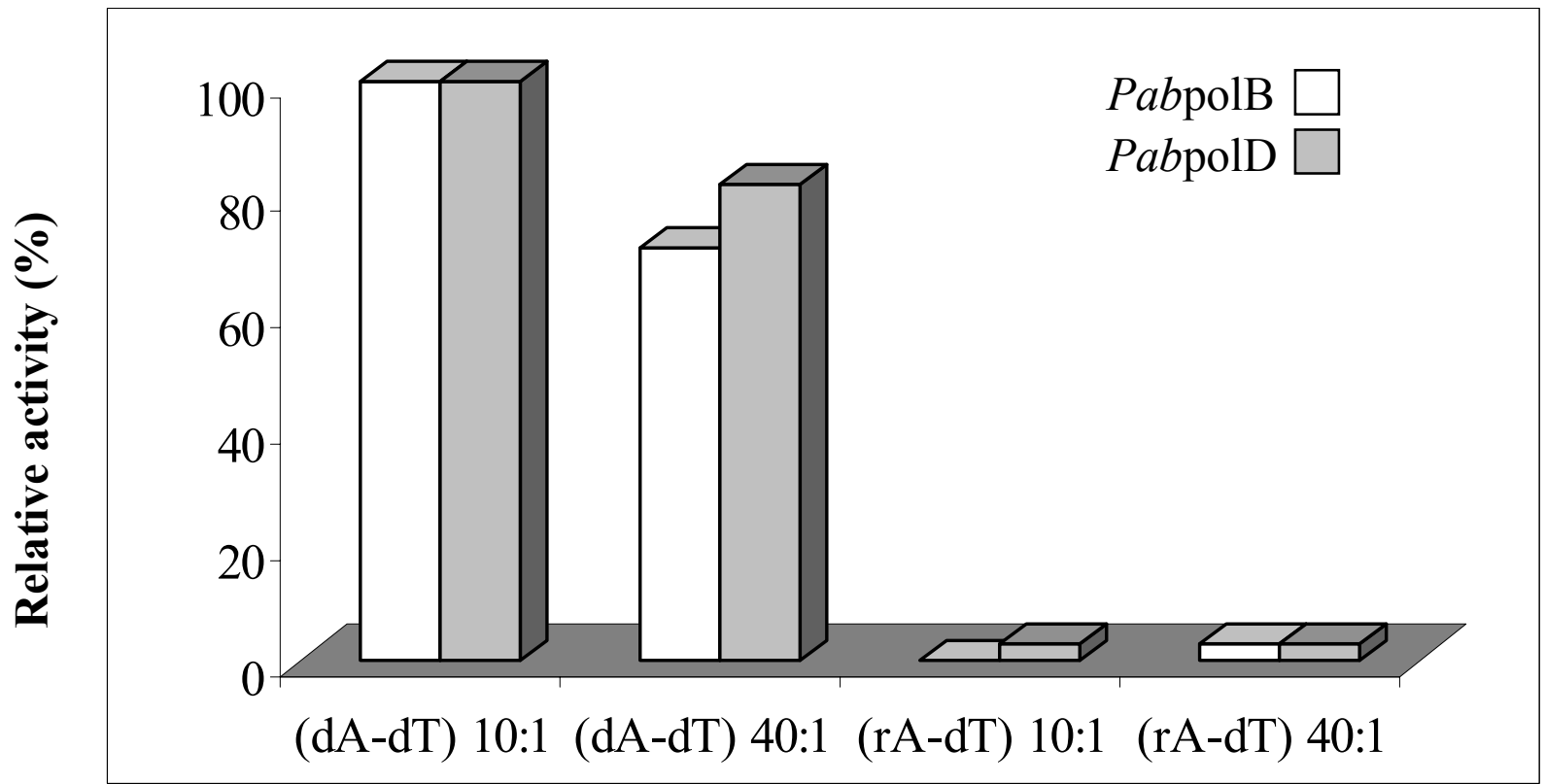


2A

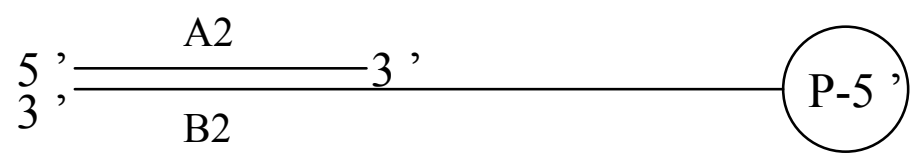

2B

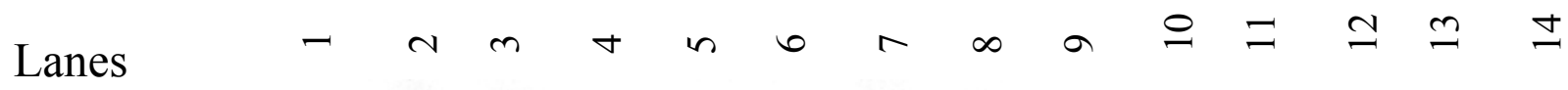
Complex

Free probe

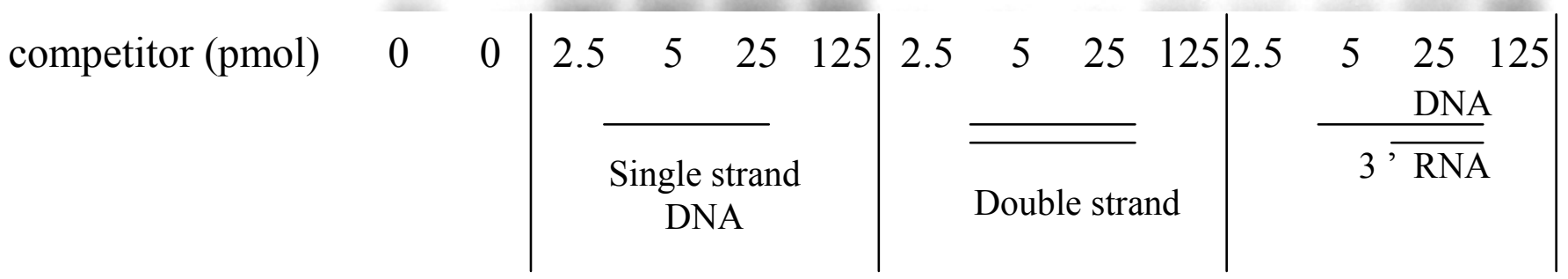

Free probe

Lanes

Complex

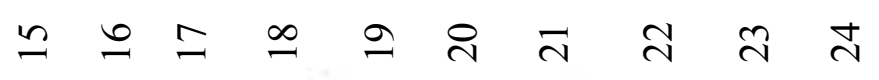

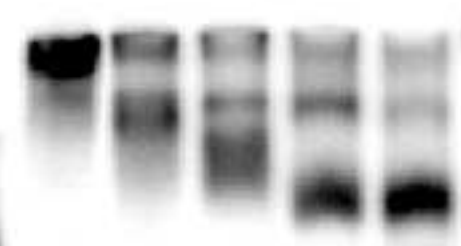

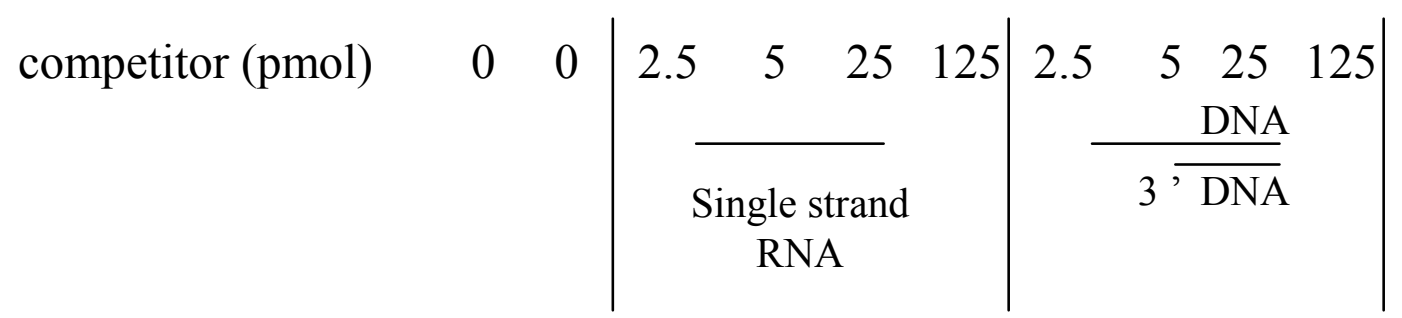


3A

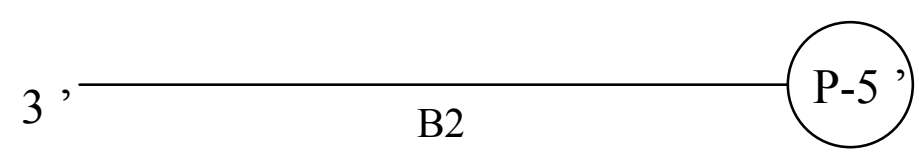

3B

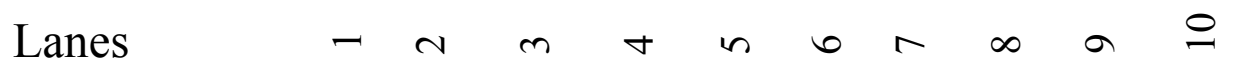

Complex

Free probe

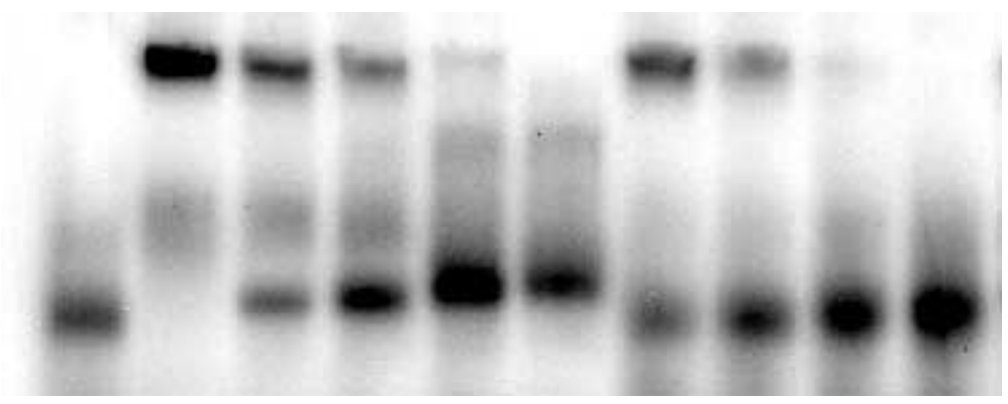

competitor (pmol)

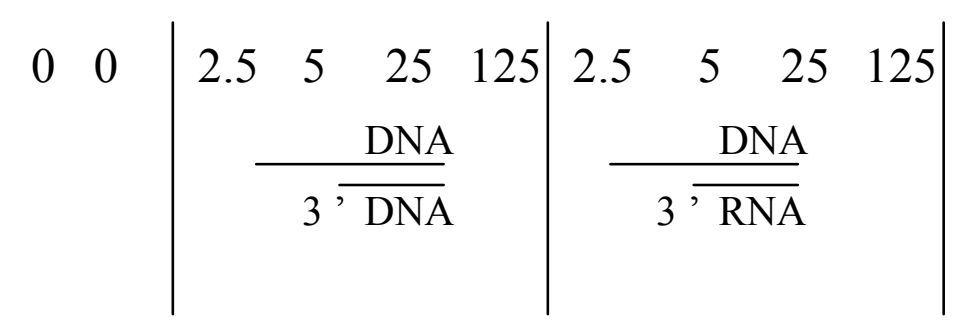

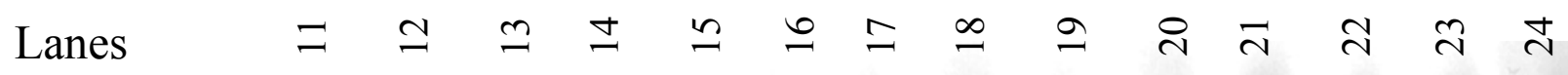

Complex

Free probe

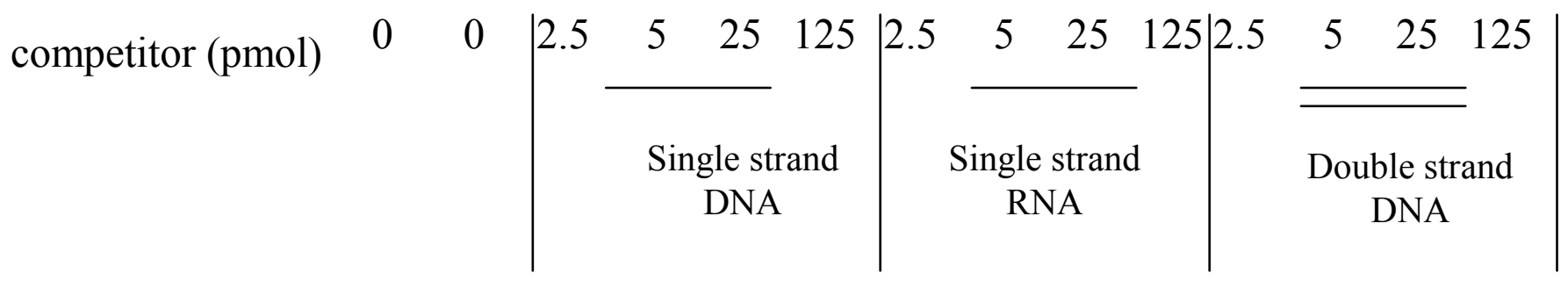


Figure4A_B

4A
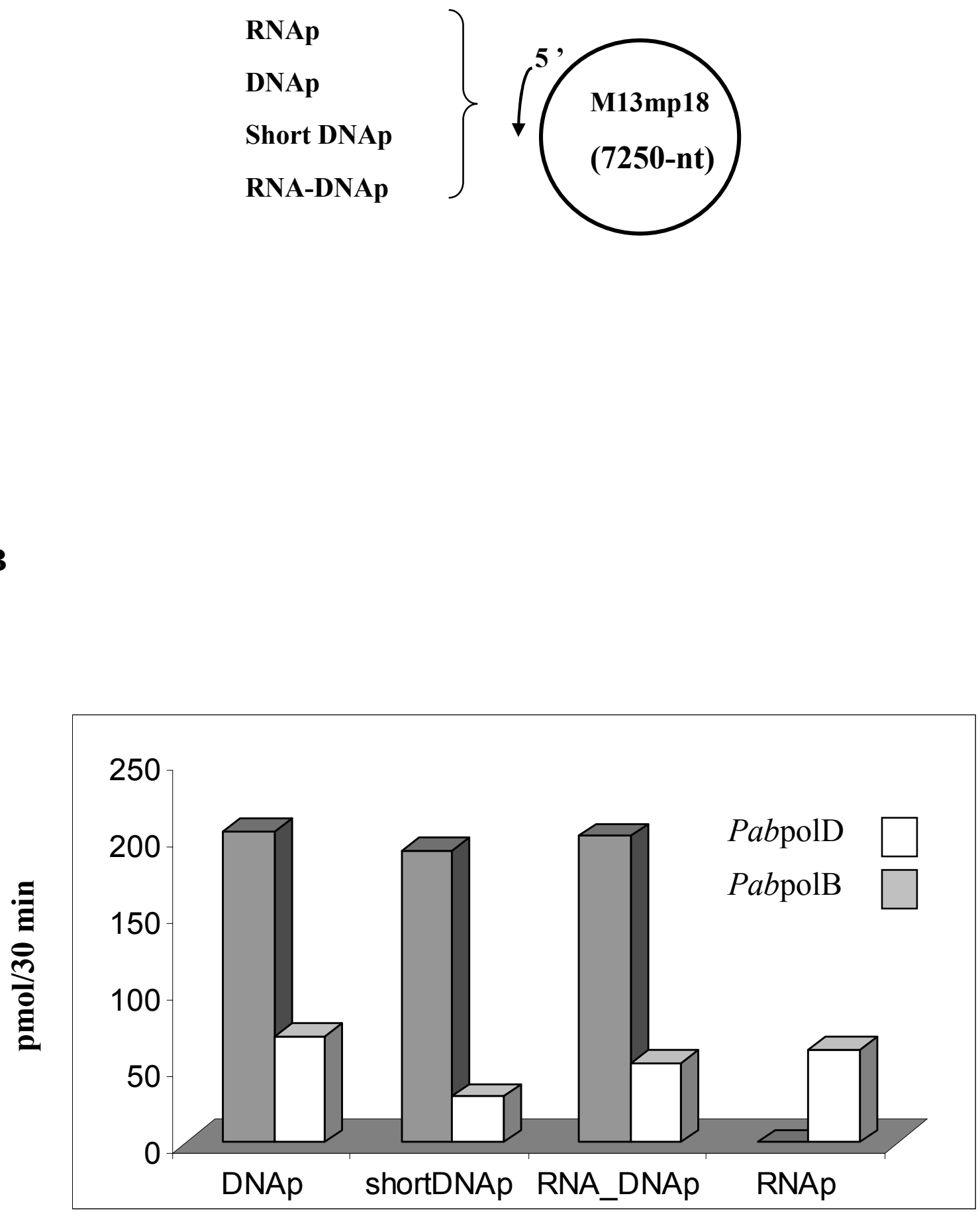


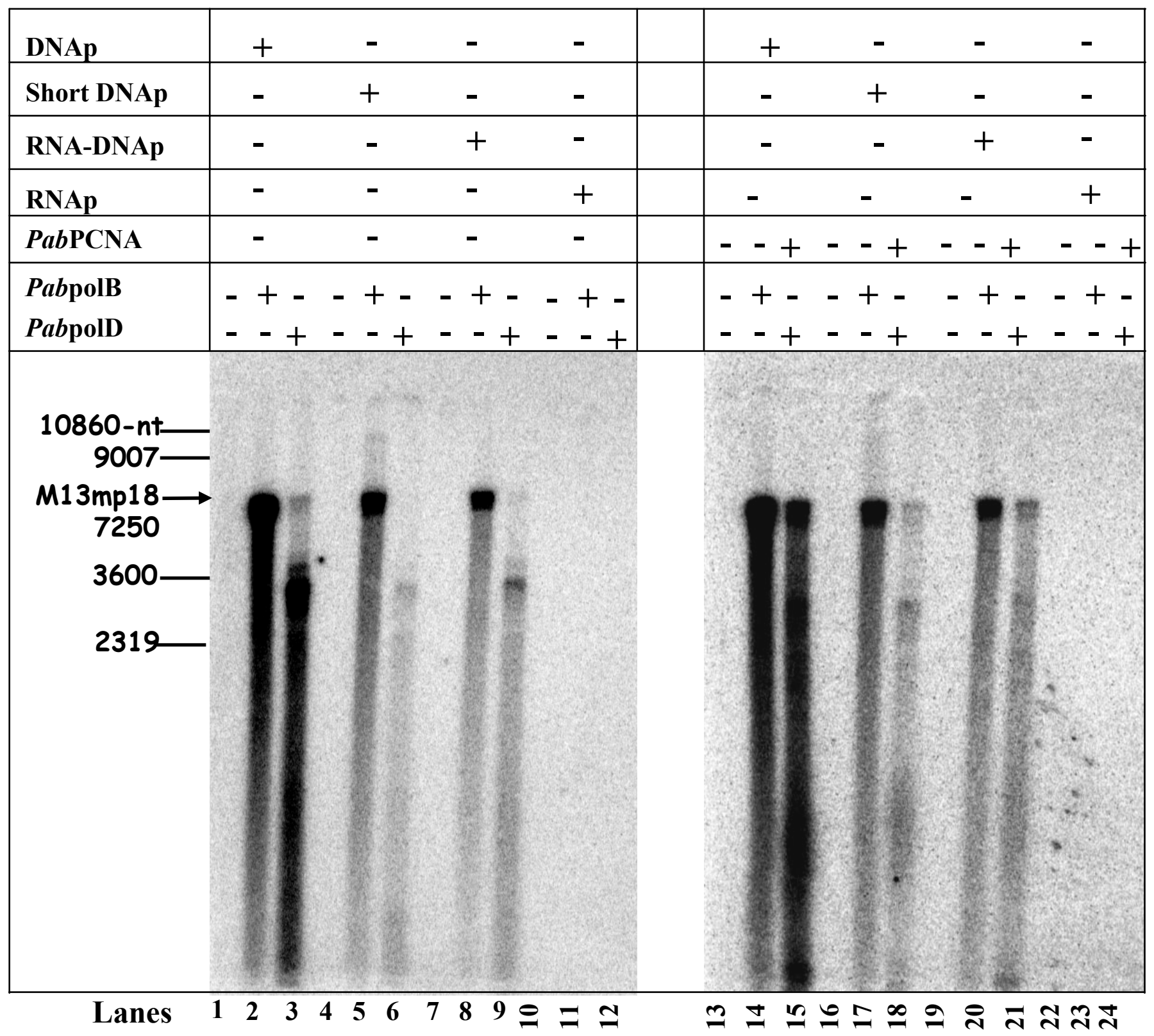

4D

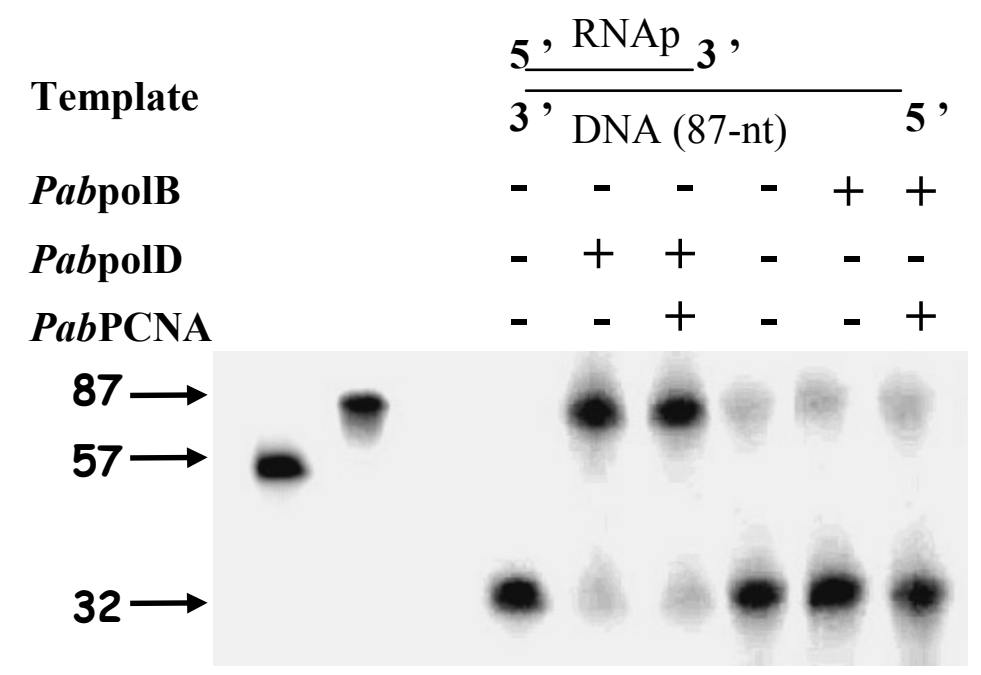


5A

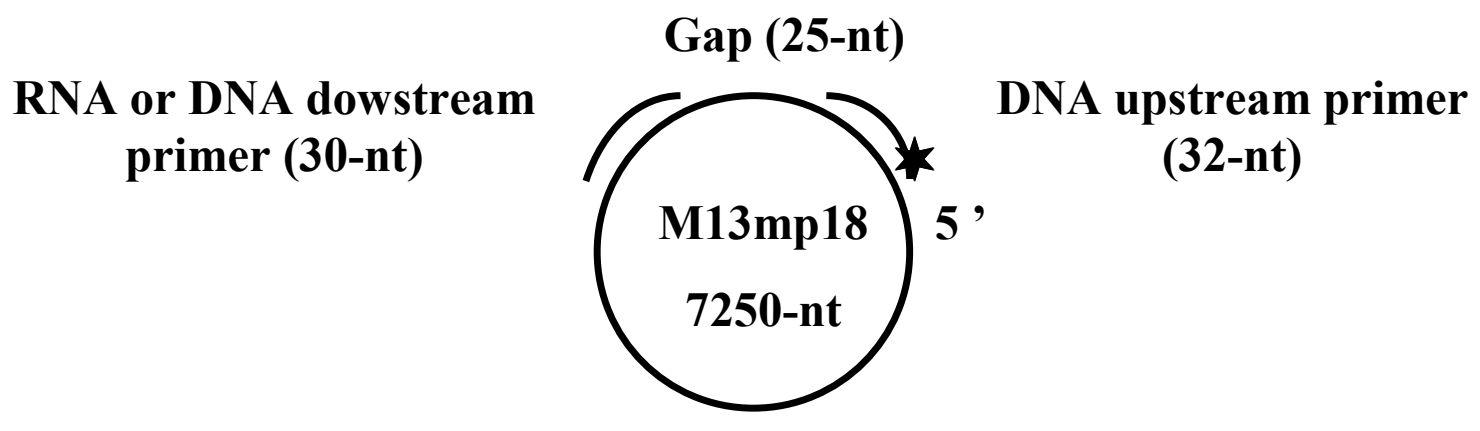

5B

Pol D

DNAd RNAd

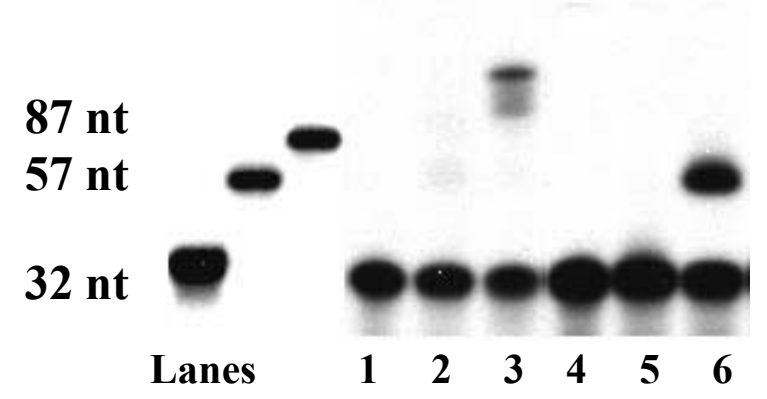

Pol B

DNAd RNAd

$87 \mathrm{nt}$

$57 \mathrm{nt}$

32 nt

$\begin{array}{llllll}7 & 8 & 9 & 10 & 11 & 12\end{array}$ 
6A

gap size $(1,10,25,50,100-n t)$

DNA or RNA dowstream primer (30-nt)

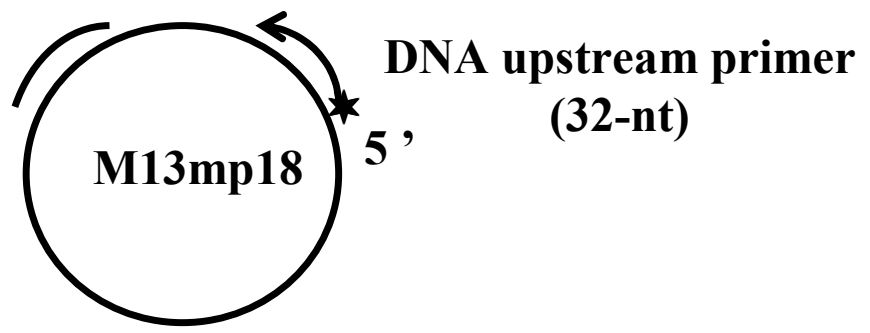

6B

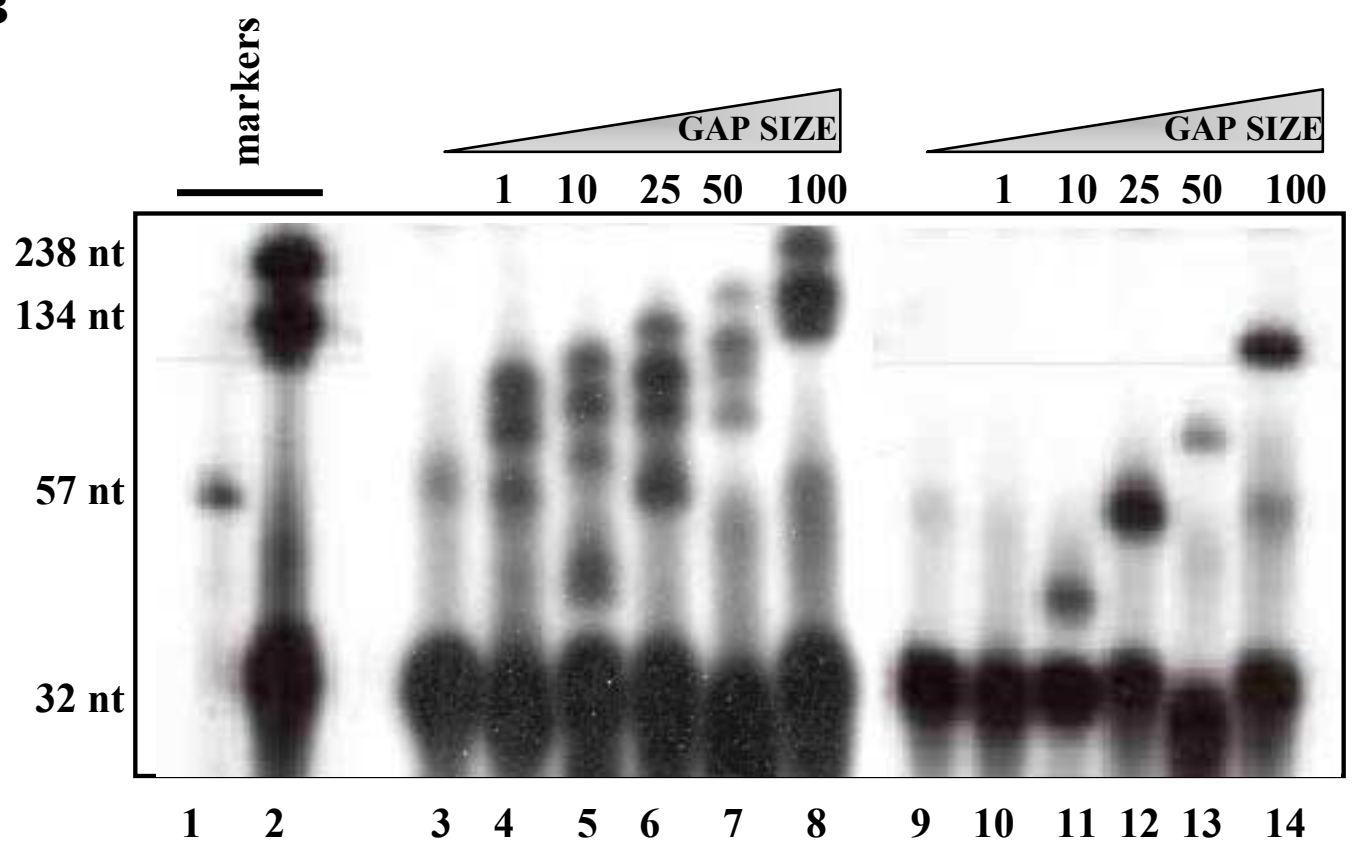

6C

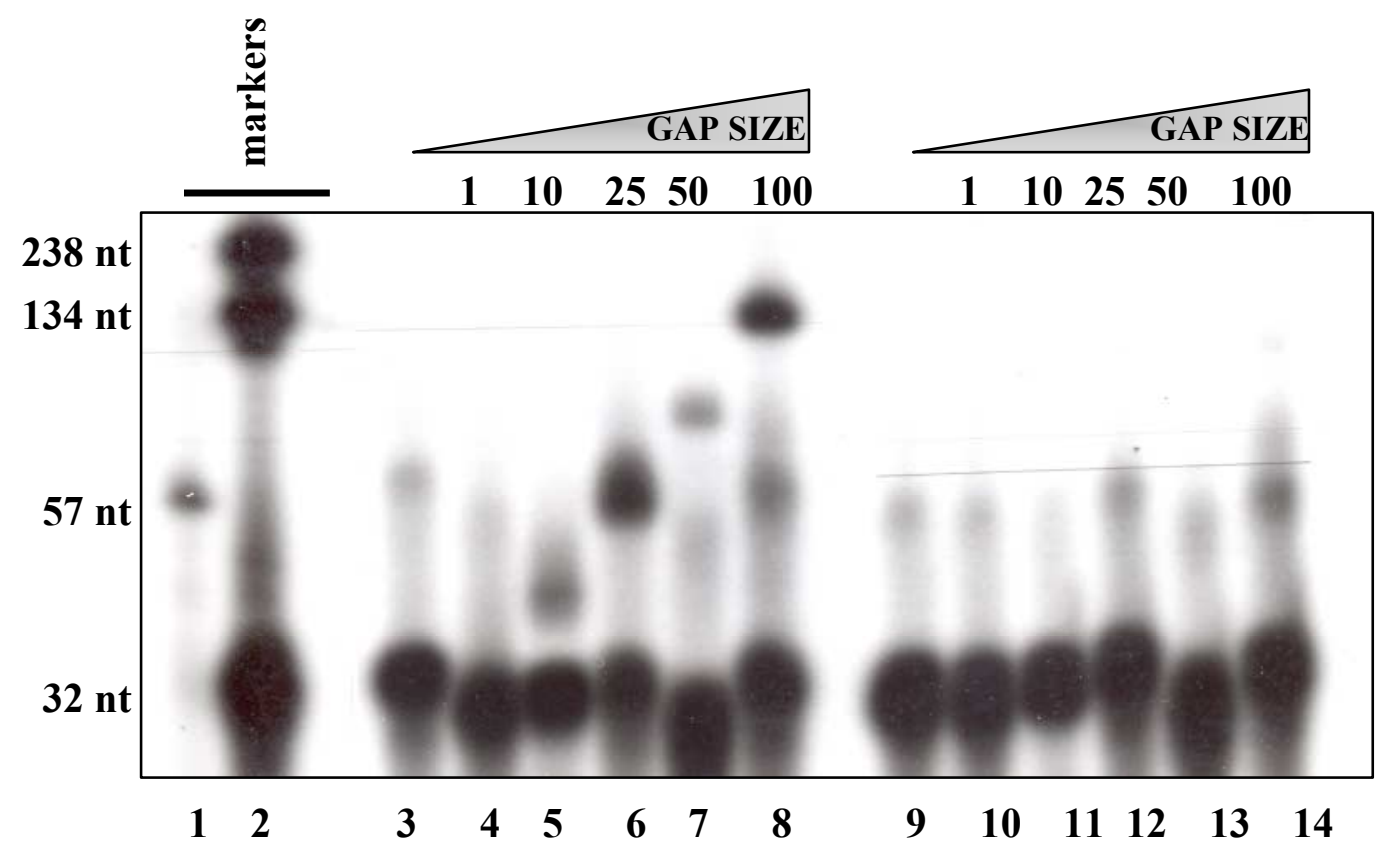


7A
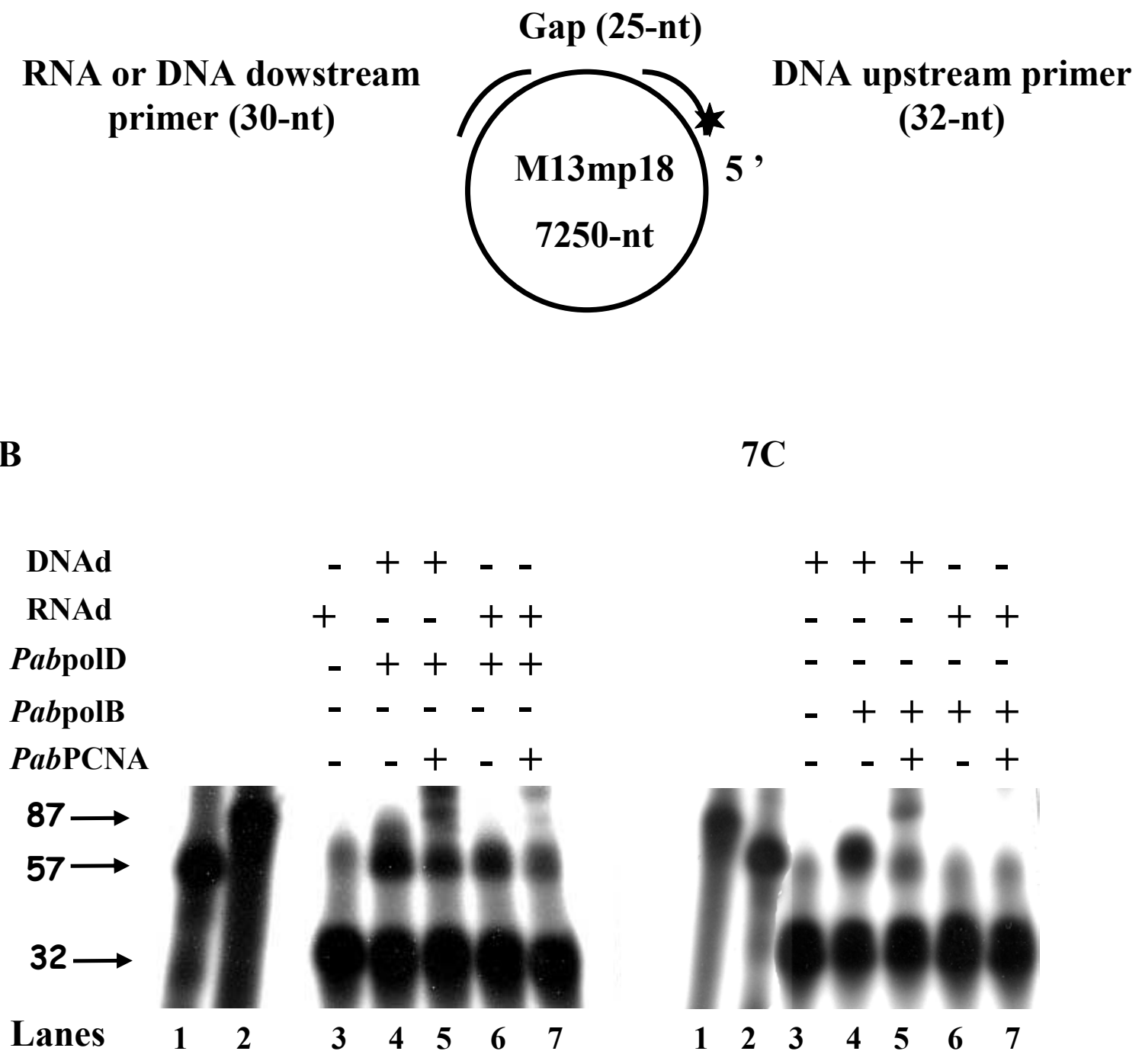
8A

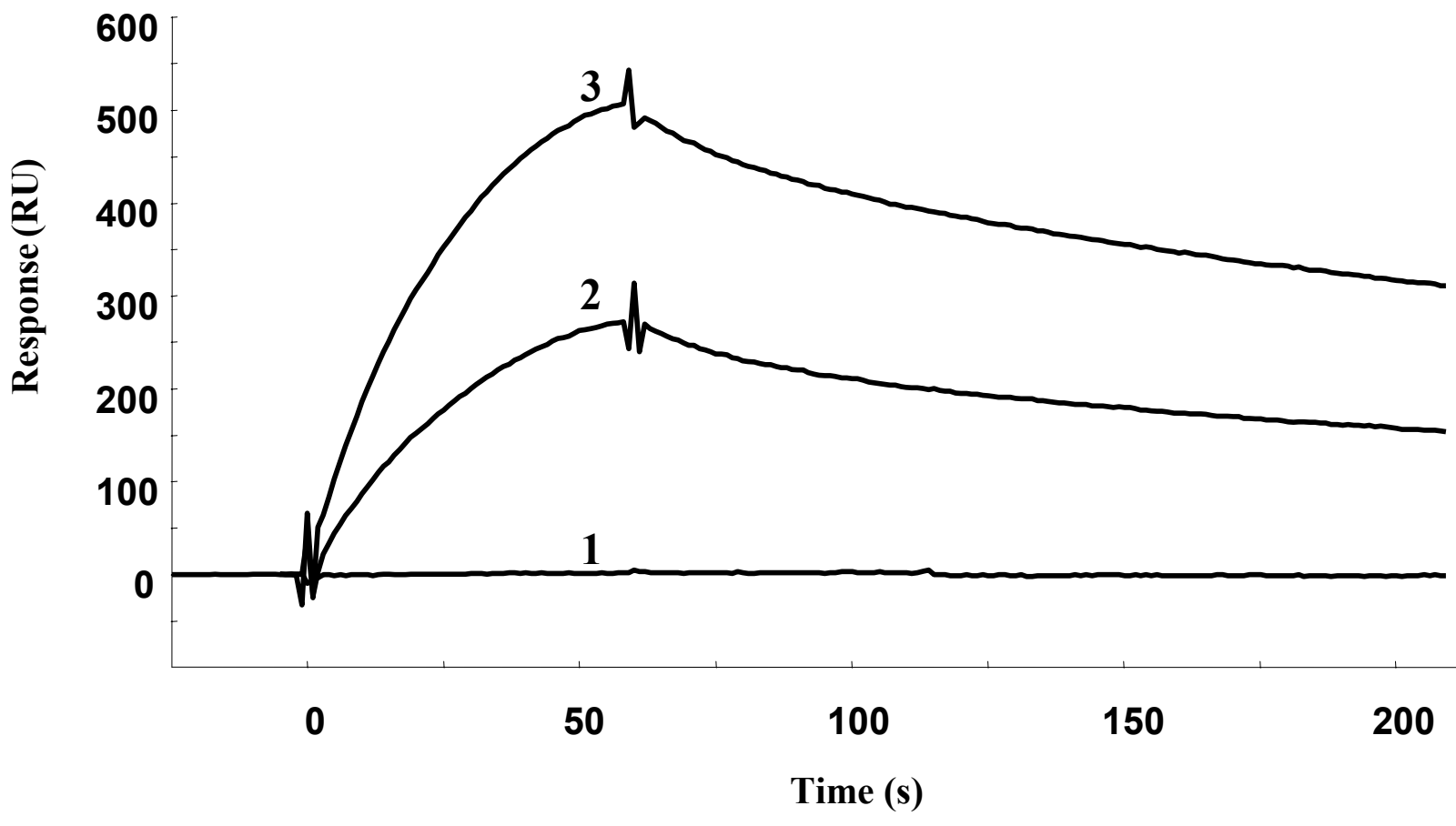

8B

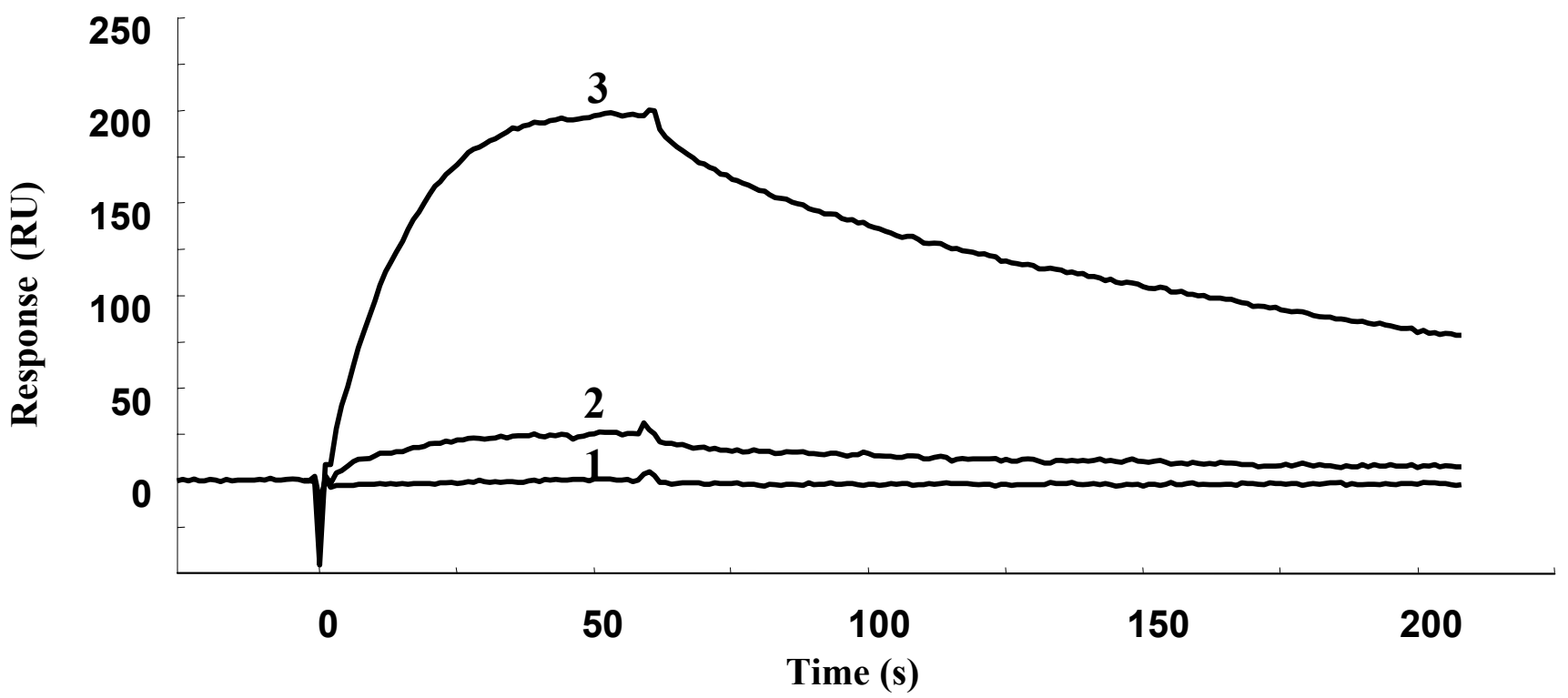


Table 1. Oligonucleotides used in this study

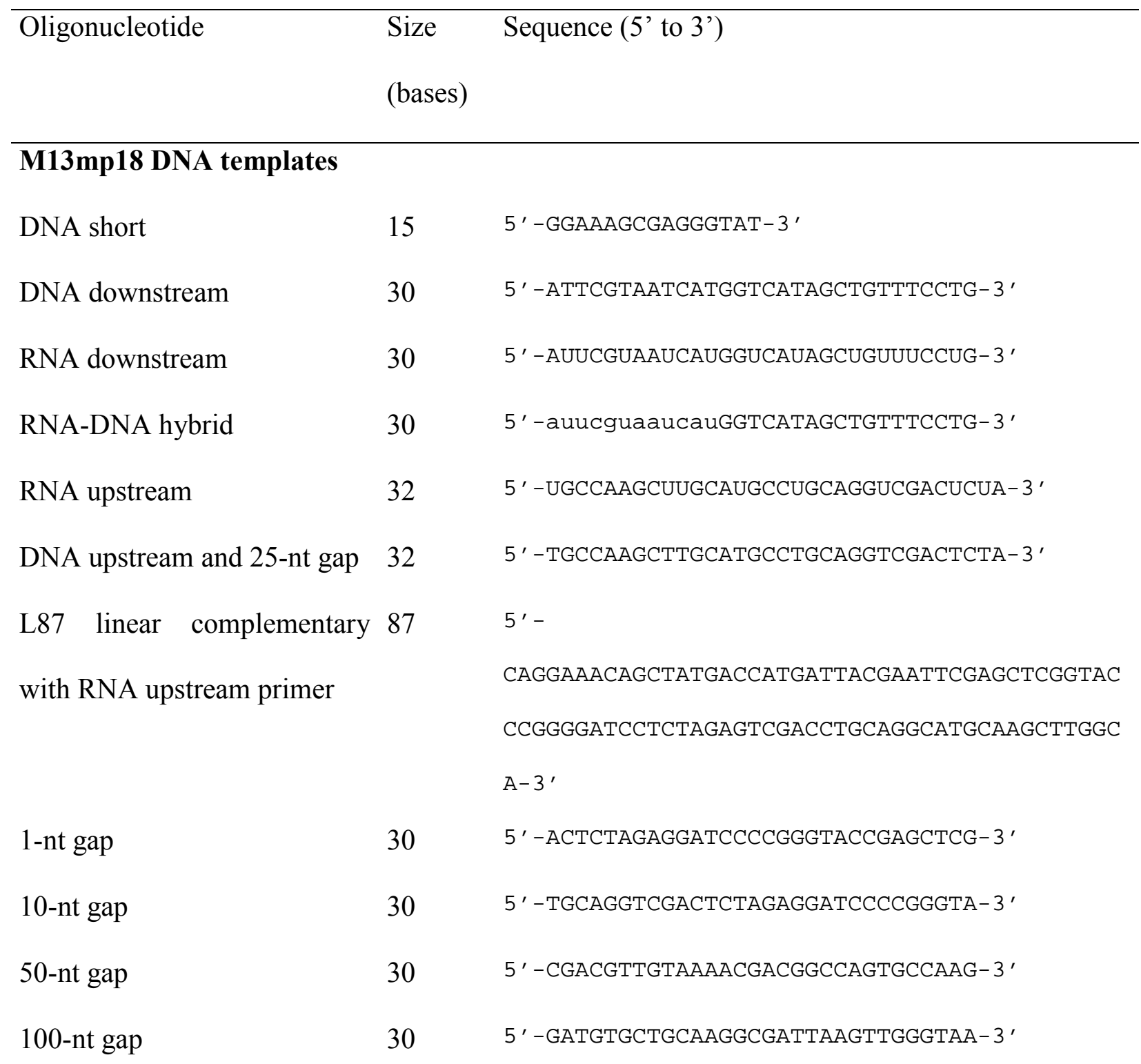

\section{EMSA and Biacore}

templates

B2 (DNA)

$75 \quad 5^{\prime}-$

GAGCTAGATGTCGGACTCTGCCTCAAGACGGGTAGTCAACGTG

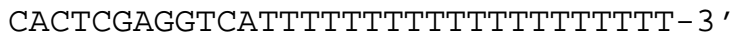

A1 (DNA) $75 \quad 5^{\prime}-$

AAAAAAAAAAAAAAAAAAAATGACCTCGAGTGCACGTTGACTA

CCCGTCTTGAGGCAGAGTCCGACATCTAGCTC-3' 
A2 (DNA)

48

$5^{\prime}-$

AAAAAAAAAAAAAAAAAAAATGACCTCGAGTGCACGTTGACTA

CCCGT $-3^{\prime}$

C1 (RNA)

48

$5^{\prime-}$

AAAAAAAAAAAAAAAAAAAAUGACCUCGAGUGCACGUUGACUA

CCCGU-3 